\title{
Accuracy of presumed uveal melanoma diagnosis before alternative therapy
}

\author{
Devron H Char, Theodore Miller
}

\begin{abstract}
Aims/Background-This study was performed to ascertain the diagnostic accuracy rate of non-invasive tests in patients with presumed uveal melanomas scheduled to be treated with either irradiation or cyclochoroidectomy.

Methods-One hundred consecutive patients who had non-invasive tests followed by fine needle aspiration biopsy (FNAB) as prior alternative treatment were analysed retrospectively.

Results-In 86 cases the diagnosis of uveal melanoma was confirmed on FNAB. In five cases false negative results were obtained. In nine patients a diagnosis other than a uveal melanoma was made on the basis of cytopathology. No significant morbidity and no evidence of tumour spread occurred.

Conclusion-In presumed uveal melanomas eligible for treatment with alternative therapies, the diagnostic accuracy of non-invasive tests is not as good as with larger tumours that require enucleation. Fine needle aspiration biopsy data resulted in correct management of $9 \%$ of cases that were thought to have uveal melanomas on non-invasive tests, but had other lesions on cytopathological evaluation.
\end{abstract}

(Brf Ophthalmol 1995; 79: 692-696)

The accuracy of diagnostic tests in patients with presumed uveal melanomas is uncertain. In tumours that require enucleation, the diagnostic accuracy reported by most ocular oncology units has been over $98 \% .{ }^{1-5}$ In smaller tumours, including those that are treated with charged particles, brachytherapy, or eye wall resection, the sensitivity of diagnostic tests is less certain.

In choroidal lesions less than $10 \mathrm{~mm}$ in diameter and less than $3 \mathrm{~mm}$ in thickness it is often impossible to differentiate a uveal melanoma from a stationary, pigmented lesion. ${ }^{4-7} \mathrm{~A}$ number of investigators have reported larger benign or metastatic uveal masses that were inadvertently mistaken for melanomas. ${ }^{8-19}$ In some series as many as $30 \%$ of anterior uveal tumours treated with modified cyclectomies, a histological diagnosis other than a uveal melanoma was found. ${ }^{20}$

The concept of uveal tumour biopsy is not new. Early attempts in the first portion of the 20th century were problematic. ${ }^{21-23}$ Approximately 20 years ago ocular oncologists, including our group, began studies with fine needle aspiration biopsy for a variety of intraocular neoplasms. ${ }^{24}$ More recently many groups have reported on diagnosis of choroidal melanomas with these techniques as well as ancillary data such as cell type, cell cycling, tissue culture propagation, ultrastructure, and measurement of nucleolar variation. ${ }^{25-32}$ In masked histology cytopathology studies we have been able to differentiate those melanomas that have or have not epithelioid tumour cells in over $95 \%$ of cases. ${ }^{3032}$ No reports of severe ocular morbidity or tumour spread have been reported, although theoretical concerns have been raised. ${ }^{33} 34$

We have managed several ciliochoroidal neoplasms that had characteristics of a uveal melanoma, on the basis of non-invasive tests, but were shown to be non-melanoma simulating lesions on cytopathological examination. Histopathological evaluation after ciliochoroidectomy confirmed these diagnoses. ${ }^{18}$ In this study we report a consecutive series of 100 patients with a presumed diagnosis of a uveal melanoma (on the basis of clinical, ultrasonographic, and fluorescein angiographic studies); a minority of these patients would have been incorrectly treated if only noninvasive diagnostic tests had been used to establish a presumptive diagnosis.

\section{Materials and methods}

We retrospectively reviewed the data from 100 consecutive patients, who had a presumptive diagnosis of uveal melanoma on the basis of non-invasive tests, and then had fine needle aspiration biopsies (FNABs) before planned insertion of an ${ }^{125} \mathrm{I}$ brachytherapy source, tantalum marker rings for charged particle treatment, or a cyclochoroidectomy. All patients were managed before July 1992 and the last follow up was obtained in September 1994.

Patients were managed in the ocular oncology unit and had given written and oral consent before all studies. All patients were initially examined with multiple observer clinical, fluorescein angiographic, and ultrasonographic techniques. On the basis of those studies a presumptive diagnosis of a uveal

Table 1 Cytopathological diagnoses

\begin{tabular}{lc}
\hline Diagnosis & Number \\
\hline Melanoma & 86 \\
False negative & 5 \\
Non-melanoma & 9 \\
Melanocytoma & 4 \\
Metastatic tumour & 3 \\
Isolated carcinoid & 1 \\
RPE proliferation & 1 \\
\hline
\end{tabular}




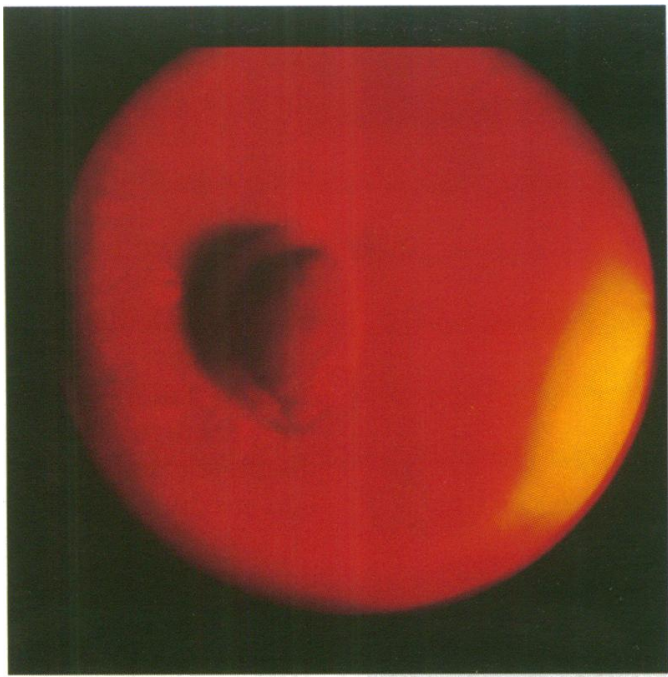

Fig $1 \mathrm{~A}$

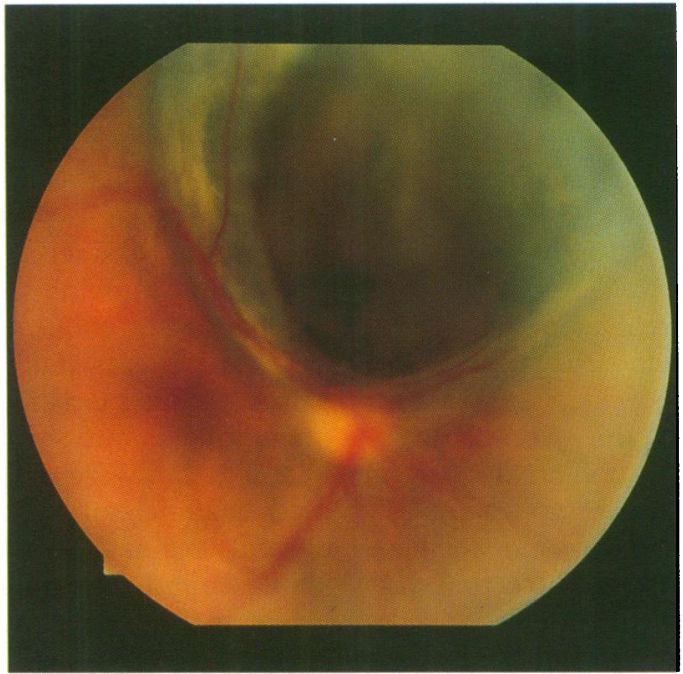

Fig $1 B$

Figure 1 Equator plus $(A)$ and conventional fundus photographs (B) of a large pigmented, peripapillary tumour with apparent retinal invasion. This was demonstrated to be a melanocytoma on cytopathological examination and on follow up the tumour has not been shown to grow.

melanoma was made and patients were scheduled for non-enucleation treatment. ${ }^{1}$

All patients had intraoperative tumour localisation before both fine needle aspiration biopsy and treatment. A limbal peritomy was fashioned, the four recti muscles were isolated and controlled with 2-0 sutures. Tumours were localised with both indirect corneal transillumination as well as by direct localisation with a point light source and indirect ophthalmoscopy. All fine needle aspiration biopsies were performed with a 25 gauge needle; most were done through a transscleral route, and some through a transvitreal approach. In all cases the site of needle entry was isolated and, as the needle was withdrawn, the site was sealed with glue.

As previously described, the specimens were all analysed initially in the operating room by a cytopathologist unaware of the clinical diagnosis. ${ }^{30}$ Material from the needle was expelled with air onto a microscope slide and a smear made in a standard manner. A quick stain was used to establish the diagnosis, and in the case of melanomas, a presumptive cell type.

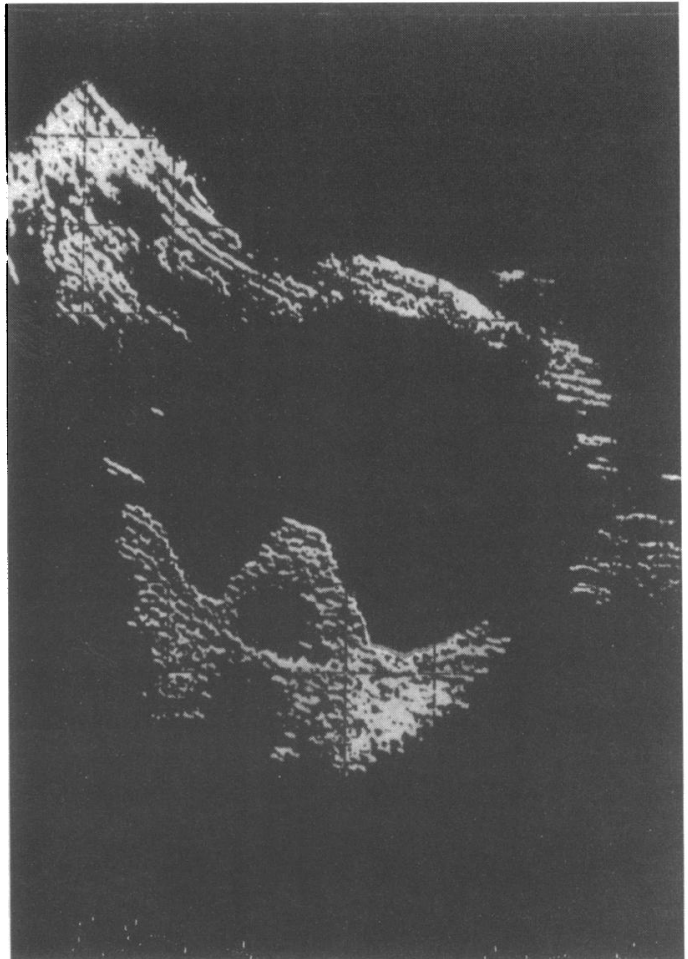

Fig $2 A$

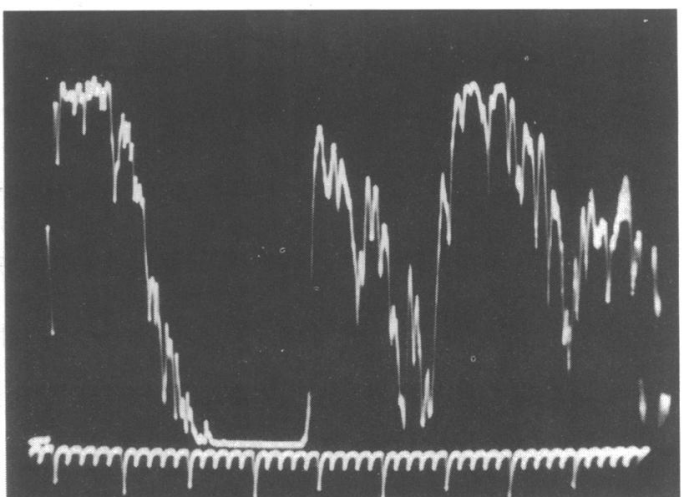

Fig $2 B$

Figure 2 Ultrasound data on case presented in Figure 1. On B-scan $(A)$ there is an internal quiet zone. On A-scan (B) there is medium to low reflectivity with a sharp posterior spike.

Treatment was then initiated (brachytherapy carrier placement, external beam radiation, surgical resection, or serial observation if a simulating lesion was diagnosed) as appropriate. Final stains, usually with Papanicolaou, were obtained. In four cases when cytological diagnosis was not certain specimens were also analysed with stains for HMB 45, S-100, oestrogen receptors, or lymphocyte markers to confirm the diagnosis.

\section{Results}

One hundred consecutive patients were brought to the operating room for treatment of a presumed uveal melanoma and had fine needle aspiration biopsies before planned therapy. These tumours all involved the choroid; 42 were posterior to the equator, 35 bridged the equator, 23 also involved a portion of the ciliary body. The mean maximum tumour diameters (based on indirect ophthalmoscopic measurements) were $12 \cdot 2 \times$ 


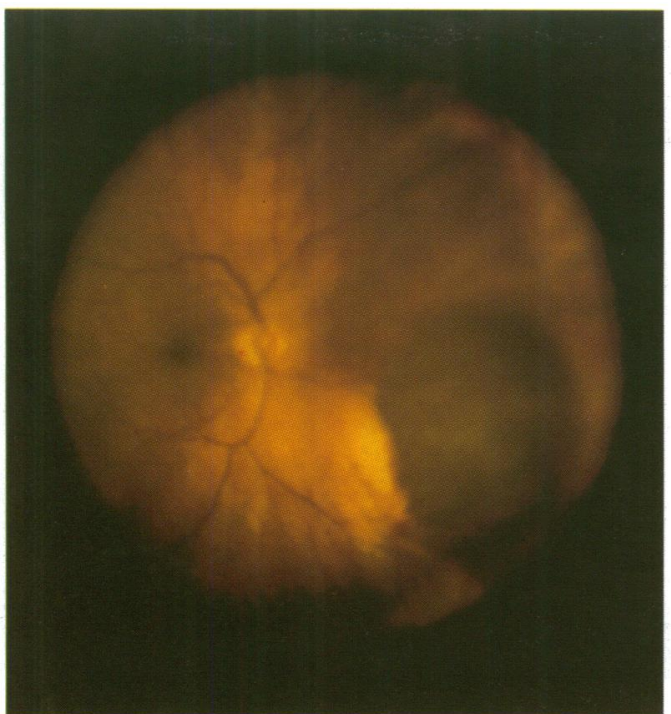

Figure 3 Equator plus fundus photograph of an isolated uveal carcinoid tumour. Metastatic evaluation was negative and the patient responded well to 40 Gy of radiation.

$10 \cdot 1 \mathrm{~mm}$. The mean tumour thickness (based on qualitative echography) was $5.8 \mathrm{~mm}$.

No significant morbidity was observed as a result of fine needle biopsy. A few patients had transient retinal or vitreal haemorrhage. No patient developed either rhegmatogenous detachment or evidence of localised tumour spread along the track of the needle. Retrospective review of our entire treated uveal melanoma patient population (approximately 1000 patients) who either did or did not have fine needle aspiration biopsies since the early 1980 s has not demonstrated any effect of needle biopsy on tumour related mortality (unpublished data).

Table 1 lists cytological diagnoses; in $86 \%$ of the cases the diagnosis of a uveal melanoma, made on the basis of non-invasive tests, was confirmed cytologically. In five cases the cytological specimen was not adequate for diagnosis. Two tumours in this later group were small growing pigmented lesions less than

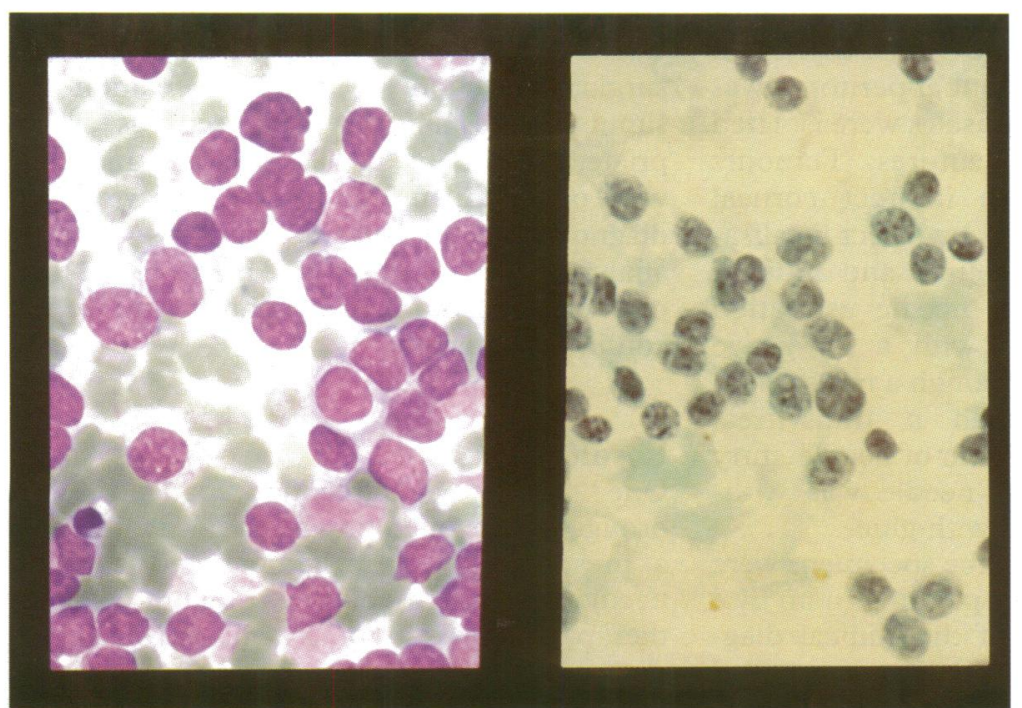

Figure 4 Cytopathology (original magnification $\times 200$ ) of case shown in Figure 3. Left is Papanicolaou stain; on the right a May-Giemsa-Grunewald stain is shown. The coarsely granular chromatin pattern in this case is most consistent with a carcinoid tumour. An HMB-45 stain was negative.
$3.5 \mathrm{~mm}$ thick, and the risk of more than one aspirate was felt not to be justified. In the other three cases, inadequate biopsies were obtained even though the lesions were over $4.5 \mathrm{~mm}$ in thickness. All cytological diagnoses were concordant with histology in the seven tumours managed with cyclochoroidectomy; three of these were benign tumours with a history of documented growth and four were melanomas.

Two patients with a known history of a systemic malignancy were biopsied. Non-invasive diagnostic test results were inconclusive; both had medium sized, amelanotic uveal tumours of uncertain aetiology; the cytopathological data confirmed the diagnoses of uveal melanomas. In nine other cases the fine needle aspiration biopsy data established a diagnosis different from melanoma.

Four patients had clinical findings of a uveal melanoma, but had a melanocytoma on cytopathological examination of fine needle aspiration biopsy material. Figure 1 shows a clinical photograph of such a very atypical tumour. Similarly, on ultrasound (Fig 2) the pattern was most consistent with a uveal melanoma. On serial evaluation over 3 years this lesion remains stable and visual acuity is unchanged at $20 / 20$.

Two patients had uveal mass lesions with some characteristics of primary uveal melanomas, but some clinical or ultrasound features that were not entirely diagnostic. Both had evidence of metastatic disease on cytological evaluation. One patient had typical clinical and ultrasonographic features of a uveal melanoma (Fig 3), but on fine needle aspiration biopsy had a lesion most consistent with an isolated primary carcinoid (Fig 4). Strains for S-100 and HMB-45 were negative, and the 2 year follow up showed no evidence of other systemic neoplasms before his death from a myocardial infarct. One patient had a presumably benign RPE tumour that had grown and was successfully resected; others had melanocytomas or metastases.

\section{Discussion}

The accuracy of uveal melanoma diagnosis in many clinical settings is uncertain. While several investigators, including our group, have shown over $99 \%$ accuracy in the diagnosis of large tumours that required enucleation, the specificity of non-invasive diagnostic tests in smaller tumours is less certain. ${ }^{1-58}$ In one enucleated series, overly optimistic accuracy rates were reported, since the diagnostically difficult cases with opaque media, were excluded from analysis. ${ }^{5}$

Pigmented choroidal tumours less than $3 \mathrm{~mm}$ in thickness and less than $10 \mathrm{~mm}$ in diameter often can not be differentiated on the basis of clinical, fluorescein, and angiographic or ultrasonographic studies. ${ }^{67}$ Fortunately, most of these cases can be followed serially and do not require therapy unless growth is documented. ${ }^{7}$ In medium size tumours the accuracy of diagnosis is less clear cut. A number of reports in the literature document 
a myriad of simulating lesions that mimic a melanoma pattern on clinical, ultrasonographic, and fluorescein angiographic studies. ${ }^{9-19}$ Some reports of surgical resection of presumed uveal melanomas document the higher rate of false diagnosis in smaller tumours or those in anterior locations. ${ }^{20}$

In this study of presumed uveal melanomas large enough to be scheduled for alternative therapy, at least $9 \%$ did not have uveal melanoma diagnosed on cytopathological evaluation of the tumour.

The implications of this study are threefold. Firstly, FNAB results had a significant impact on management. Some patients who require therapy for tumours that are not large enough to require enucleation are not correctly diagnosed on the basis of non-invasive tests. In some of these cases radiation therapy is not required. Radiation morbidity can be avoided in such patients with correct diagnosis. In others, an ineffective radiation dose would have been delivered with subsequent treatment failure if the results of only non-invasive tests would have been used to plan treatment. Two patients, with presumed metastatic lesions that were shown to be primary melanomas, would have received inadequate radiation. We have seen this misdiagnosis occur previously, with subsequent referral to us when the presumed metastasis continues to grow after receiving approximately $40 \mathrm{~Gy}$ of photon irradiation. In two other patients with non-invasive test data most consistent with a melanoma, metastatic choroidal tumours were diagnosed with FNAB. These later two patients were therefore treated with a lower dose of radiation $(40 \mathrm{~Gy})$ and presumably lower complications than had they received a higher dose needed for a melanoma. Secondly, in studies of uveal melanoma mortality after radiation it is likely that a minority of patients thought to have melanoma may not, in fact, have intraocular neoplasms associated with tumour related mortality. It is thus possible that the survival reported after some series of irradiated uveal melanomas may be slightly better because of inclusion of these atypical, simulating lesions. Thirdly, this study and a number of others continue to document the very low observed morbidity associated with uveal melanoma fine needle aspiration biopsy. ${ }^{24-32}$ While some investigators have noted small numbers of tumour cells in the needle track, there are no reports of spread of uveal melanoma as a result of fine needle aspiration biopsy. ${ }^{33} 34$

No significant complications were noted from needle biopsy in this study; however, several important caveats need to be emphasised. (1) While in this trial we performed FNABs on all patients who required alternative invasive therapy; this is not our routine clinical practice, and patients outside of this study who have classic findings on non-invasive tests do not have needle biopsies. Similarly, patients with very large tumours scheduled for enucleation did not routinely have fine needle aspiration biopsies. (2) The accuracy of FNAB is almost entirely dependent on the skill and techniques used in cytopathology. In our experience, where needle biopsies are immediately analysed in the operating room, the incidence of false negative biopsies is $<5 \%$; some centres with delayed processing at an adjacent institution have noted as high as a $25 \%$ inadequate specimen rate. ${ }^{35}$ Cytological evaluation in the operating room allows a second biopsy attempt if the first specimen is inadequate. This approach lowers, but does not eliminate, false negative results. (3) Accuracy of cell type classification is almost wholly dependent on the skill of the cytopathologist, but should be as high as $95 \%$ with the techniques we have used. (4) It is uncertain with multivariate analysis how prognostically important cytological cell type classification is when compared with clinical measures of survival such as patient age, largest tumour size, and tumour location. (5) While at last follow up, the clinical response of patients who were treated without surgical resection is concordant with their cytopathological diagnosis, longer follow up may demonstrate some change. In resected uveal melanocytomas the cytopathology and histology were congruent. It is possible that a false negative result could occur using these techniques; however, we have not observed that to date. In none of the patients with benign cytological diagnosis has growth occurred; however, longer follow up, such as in the case presented in Figure 1, might show growth. Certainly there have been rare reports of melanocytomas undergoing malignant regeneration, and sampling 'error' could occur in such a case where a malignant degenerative focus of tumour could be not sampled and therefore considered a benign lesion.

This work was supported in part by That Man May See, Research to Prevent Blindness.

1 Char DH, Stone RD, Irvine AR, Crawford JB, Hilton GF, Lonn LI, et al. Diagnostic modalities in choroidal Lonn LI, et al. Diagnostic modalities in

2 Shields JA, McDonald PR. Improvements in the diagnosis of posterior uveal melanomas. Arch Ophthalmol 1974; 91: 259-66.

3 Robertson DM, Campbell PJ. Errors in the diagnosis of malignant melanoma to the choroid. Am $\mathcal{f}$ Ophthalmol 1979; 87: 269-75.

4 Gass JD. Problems in the differential diagnosis of choroidal nevi and malignant melanoma XXXIII Edward Jackson Memorial lecture. Trans Am Acad Ophthalmol Otolaryngol 1977; 83: 19-48.

5 Accuracy of diagnosis of choroidal melanomas in the Collaborative Ocular Melanoma Study. COMS report no Collaborative Ocular Melanoma Study. CO
1. Arch Ophthalmol 1990; 108: 1268-73.

6 Char DH, Hogan MJ. Management of small pigmented choroidal lesions. Br f Ophthalmol 1977; 61: 54-8.

7 Butler P, Char DH, Zarbin M, Kroll S. Natural history of indeterminant pigmented choroidal mass lesions. Ophthalmology 1994; 101: 710-6.

8 Char DH. Clinical ocular oncology. New York: Churchill Livingstone, 1989.

9 Shields JA. Lesions simulating malignant melanoma of the posterior uvea. Arch Ophthalmol 1973; 89: 466-71.

10 Ryan SJ, Zimmerman LE, King FM. Reactive lymphoid hyperplasia: an unusual form of intraocular pseudotumor. Trans Am Acad Ophthalmol Otol Soc 1972; 76: 652-71.

11 Cibis GW, Fratkin J. Hemorrhage into retinoschisis diagnosed as malignant melanoma. Am $\mathcal{f}$ Ophthalmol 1979;
87: 96-7.

12 Packard RB, Harry J. Choroidal neurilemmoma: an unusual clinical misdiagnosis. Br f Ophthalmol 1981; 65: 189-91.

13 Lipper S, Eifrig DE, Peiffer RL, Bagnell CR. Chorioretinal foreign body simulating malignant melanoma. Am $\mathcal{f}$ Ophthalmol 1981; 92: 202-5.

14 Shields JA, Font RL. Melanocytoma of the choroid clinically simulating a malignant melanoma. Arch Ophthalmol 1972; 87: 396-400.

15 Fredrick DR, Char DH, Ljung BM, Brinton DA. Solitary intraocular lymphoma as an initial presentation of widespread disease. Arch Ophthalmol 1989; 107: 395-7.

16 Bardenstein DS, Char DH, Jones C, Crawford JB, Miller 
TR, Riekhof FT. Metastatic ciliary body carcinoid tumor. Arch Ophthalmol 1990; 108: 1590-4.

17 Smith PA, Damato BE, Ko MK, Lyness RW. Anterio uveal neurilemmoma: a rare neoplasm simulating malignant melanoma. $B r$ F Ophthalmol 1987; 71: 34-40.

18 Char DH, Miller TR, Crawford JB. Cytopathologic diagnosis of benign lesions simulating choroidal melanomas. Am $₹$ Ophthalmol 1991; 112: 70-5.

19 Strempel I. Rare choroidal tumor simulating a malignant melanoma. Ophthalmologica 1991; 202: 110-4.

20 Peyman GA, Charles H. Internal eye wall resection in the management of uveal melanoma. Can $\mathcal{F}$ Ophthalmol 1988; 23: 218-23.

21 Meisner W. Zur Diagnose des Aderhautsakrom. Klin Monatsbl Augenheilkd 1923; 70: 722-32.

22 Esser F. Zur Diagnose des Aderhaut-Sakoms. Klin Monatsb Augenheilkd 1924; 73: 192-4.

23 Jensen O, Anderson S. Late complications of biopsy of intraocular tumors. Arch Ophthalmol 1957; 37: 568-72.

24 Jakobiec FA, Coleman DR, Chattock A, Smith $M$ Ultrasonically guided needle biopsy and cytologic diagnosis of solid intraocular tumors. Ophthalmology 1979; 86: nosis of solid
$1662-78$.

25 Czerniak B, Woyke S, Domagala W, Krzysztolik Z. Fine needle aspiration cytology of intraocular malignant melanoma. Acta Cytol 1983; 27: 157-65.

26 Augsburger JJ, Shields JA. Fine needle aspiration biopsy of solid intraocular tumors: indications, instrumentation and techniques. Ophthalmic Surg 1984; 15: 34-40.

27 Folberg R, Augsburger JJ, Gamel JW, Shields JA, Lang WR. Fine needle aspirates of uveal melanomas and prognosis. Am f Ophthalmol 1985; 100: 654-7.
28 Schachat AP, Newsome DA, Miller E, McDonnell PJ, Green WR, LaFrance $N$. Tissue culture of human choroidal melanoma cells obtained by fine needle aspiration biopsy. Graefes Arch Clin Exp Ophthalmol 1986; 224 407-13.

29 Char DH, Gonzales J, Crawford JB, Miller T. Iris melanoma with increased intraocular pressure: differentiation of focal solitary from diffuse or multiple tumors. Arch Ophthalmol 1989; 107: 548-51.

30 Char DH, Miller T, Ljung BM, Howes E, Stoloff A. Fine needle aspiration biopsy in uveal melanoma. Acta Cytol 1989; 33: 559-605.

31 Kindy-Degnan N, Char DH, Swift P, Kaleta S, Ljung BM Bromodeoxyuridine uptake in the assessment of intraocular tumor therapy. Arch Ophthalmol 1989; 107: 746-55.

32 Char DH, Kroll SM, Stoloff A, Kaleta-Michaels S Crawford JB, Miller TR, et al. Cytomorphometry of uvea melanomas: fine needle aspiration biopsy versus standard histology. Analytical and Quantitative Cytology and Histology 1991; 13: 293-9.

33 Karcioglu ZA, Gordon RA, Karcioglu GL. Tumor seeding in ocular fine needle aspiration biopsy. Ophthalmology 1985; 92: 1763-7.

34 Glasgow BJ, Brown HH, Zargoza AM, Foos RY. Quantitation of tumor seeding from fine needle aspiration of ocular melanomas. Am $\mathcal{F}$ Ophthalmol 1988; 105: 538-46.

35 Shields JA, Shields CL, Enya H, Eagle RC Jr, De Potter P. Fine needle aspiration biopsy of suspected intraocular tumors. Ophthalmology 1993; 100: 1677-84. 